\title{
RESPONSABILIDAD DE LA EMPRESA PRINCIPAL EN EL PROCEDIMIENTO DE TUTELA LABORAL
}

\author{
RODRIGO SANHUEZA TORRES \\ Abogado
}

\begin{abstract}
RESUMEN: La responsabilidad de la empresa principal en el procedimiento de tutela laboral es un tema de creciente interés en nuestra doctrina y jurisprudencia, a raíz del incipiente aumento de las denuncias de vulneración de derechos fundamentales por parte de los trabajadores de la empresa contratista, que buscan que la empresa principal responda en forma solidaria o subsidiaria en virtud del artículo 183-B del Código del Trabajo. En este trabajo, pretendemos demostrar que la empresa principal no debe responder, ni siquiera subsidiariamente, en caso de una condena por vulneración de derechos fundamentales de un trabajador de la empresa contratista. Solamente debe responder el agente que realizó la acción vulneratoria.
\end{abstract}

Palabras clave: Tutela laboral, derechos fundamentales, empresa principal, responsabilidad solidaria, responsabilidad subsidiaria.

\begin{abstract}
The responsibility of the lead company in the process of labor protection is a topic of growing interest in our doctrine and jurisprudence, following the initial increase in reported violations of the fundamental rights of the contractor company's workers, who seek that the lead company responds in joint liability or subsidiarily under Article 183-B of the Labour Code. In this paper we pretend to demonstrate that the lead company should not respond, not even subsidiarily, in case of a conviction for violation of the fundamental rights of an employee of the contractor company. It is only needed that the agent who performed the damaging action responds.
\end{abstract}

Key words: labor tutelage, fundamental rights, lead company, joint liability, subsidiary liability.

\section{INTRODUCCIONN}

La entrada en vigencia del nuevo procedimiento laboral ha traído como consecuencia la traducción procesal la idea de la eficacia horizontal de los derechos fundamentales, es decir, de la aplicación en forma directa de las normas constitucionales entre particulares. En efecto, el propósito de este procedimiento no es otro que potenciar la vigencia plena, en el ámbito jurídico-laboral, de los derechos que el trabajador posee no solo en cuanto trabajador sino también en su condición de persona, de tal forma que nuestro ordenamiento jurídico cuente con un procedimiento especial que asegure la adecuada y eficaz protección de las garantías establecidas en la Constitución Política de la República ${ }^{1}$. Dicho procedimiento, sumado a la celeridad que la nueva justicia laboral le ha otorgado a las causas laborales ${ }^{2}$, trajo como consecuencia la posibilidad de una verdadera justicia para los trabajadores, quienes finalmente cuentan con un procedimiento apto para lograr equiparar una relación jurídica consustancialmente desigual.

\footnotetext{
Abogado. Pontificia Universidad Católica de Chile.

1 Ley $N^{\circ}$ 20.087. Mensaje $N^{\circ} 4-350.22$ de septiembre de 2003. Punto III, No 8.

2 Según estadísticas del Ministerio de Justicia, el tiempo promedio de tramitación de demandas de aplicación general es de 58 días, lo que es ciertamente inferior a los casi 2 años que demoraba la tramitación de las demandas laborales en el sistema antiguo. Al respecto, ver: http://web.minjusticia.cl/laboral/estadisticas.php
} 
Es que no cabe duda que Chile, desde el punto de vista laboral, es un país que todavía no alcanza una verdadera cultura de respeto a las garantías constitucionales de los trabajadores. En efecto, nuestro país todavía cuenta con grandes diferencias de remuneraciones entre hombres y mujeres que hacen el mismo trabajo ${ }^{3}$, todavía la clase social y colegio de origen son un factor determinante para la contratación ${ }^{4}$, todavía los trabajadores extranjeros, especialmente latinoamericanos, laboran en condiciones bastante más precarias que los nacionales ${ }^{5}$, entre otros importantes problemas que forman parte de la agenda pública nacional. Por todo esto, que el procedimiento de tutela laboral garantice que el principio de supremacía constitucional se haga presente en cada conflicto jurídico-laboral, asegurando así, la existencia de mecanismos idóneos que permitan que las garantías constitucionales se apliquen para todos, y eventualmente contra todos, es una medida extremadamente positiva para nuestra legislación.

Sin embargo, bien vale preguntarse: ‘a qué costo se pretende asegurar el reparo de toda vulneración de derechos fundamentales? La necesidad de que estas sean reparadas: ¿significa que un individuo u organización que no tuvo participación en los hechos tenga la obligación de responder? En este sentido, nuestra respuesta es negativa: no creemos que todo aquel partícipe de una relación laboral deba necesariamente responder de una infracción a los derechos fundamentales de un trabajador, y llevándolo al tema en concreto del presente trabajo, no creemos que, en el contexto de una relación laboral de subcontratación, la empresa principal deba de responder, ni siquiera subsidiariamente, en caso de una condena por vulneración de derechos fundamentales de un trabajador de la empresa contratista. Solamente debería de responder el agente que realizó la acción vulneratoria.

\footnotetext{
3 De acuerdo a la Encuesta Humanas "Percepción de las Mujeres sobre su Situación y Condiciones de Vida en Chile 2011", el $84 \%$ de las mujeres chilenas cree que hay discriminación laboral hacia ellas. A mayor abundamiento, las estadísticas entregadas el año 2011 por el Centro de Estudios del SERNAM señalan que una mujer que ocupa el mismo cargo que un hombre gana, en promedio, entre un $30 \%$ a $50 \%$ menos.

4 Un estudio publicado por el diario La Tercera el 30 de mayo de 2008 demuestra que el $50 \%$ de los gerentes generales de las más grandes empresas del país provienen exclusivamente de cinco colegios de elite: Verbo Divino, Sagrados Corazones de Manquehue, Saint George, San Ignacio y Tabancura, colegios que representan el 0,04\% de todos los colegios del país. Sin embargo, conviene hacer presente que según los últimos estudios, Chile pareciese tener un avance en esta materia. A este respecto, existe un interesantísimo estudio por parte de los investigadores David Bravo, Claudia Sanhueza y Sergio Urzúa del año 2008 , el que consistió en el envío de más de mil currículum vítae a personas ofreciendo empleo en el diario El Mercurio (empleos calificados, semicalificados y no calificados), utilizando nombres falsos según clase social ("Pedro Ariztía Larraín" y "Clinton Benaldo González"). Los resultados demostraron que prácticamente ambos nombres tuvieron la misma cantidad de respuestas, lo cual preliminarmente es un indicio bastante positivo, pero que no es particularmente concluyente, toda vez que no existió proceso de entrevista, en donde pudo haber existido algún tipo de discriminación. Al respecto, ver: BRAvo, David; SANHUEZA, Claudia y URZÚA, Sergio. "Ability, schooling choices and gender labor market discrimination: evidence for Chile", en Research Network Working, paper, No R-558. Estados Unidos, Washington, D.C.: Banco Interamericano de Desarrollo, 2008.

5 De acuerdo a un estudio del año 2008 de Gemines y la Universidad Finis Terra, el $70 \%$ de los encuestados mira en menos a los inmigrantes latinoamericanos. A su vez, la Dirección del Trabajo informó que el año 2011 aumentaron en un $21 \%$ las denuncias de trabajadores extranjeros ante la Dirección del Trabajo, siendo los reclamos más recurrentes por remuneraciones, cotizaciones previsionales e higiene y seguridad.
} 


\section{BREVE RESEÑA SOBRE EL PROCEDIMIENTO DE TUTELA DE DERECHOS FUNDAMENTALES}

La Constitución Política de la República contiene diversas garantías constitucionales específicas en materia laboral, tales como la libertad de trabajo y su protección, la justa retribución y la libertad sindical. Además, reconoce varios otros derechos fundamentales que se relacionan directamente con lo que en doctrina se conoce como "ciudadanía en la empresa"6, tales como la integridad física y psíquica, la vida privada, la honra, etc.

Sin embargo, y pese a lo señalado expresamente por el inciso segundo del artículo 6 de la Constitución ${ }^{7}$, no es posible afirmar que previo al procedimiento de tutela de derechos fundamentales nuestro ordenamiento jurídico satisficiese las exigencias del principio de vinculación directa de la Constitución en el ámbito específico de las relaciones laborales. Con anterioridad a este procedimiento, la única vía para hacer valer estos derechos era el recurso de protección, vía que resultaba completamente inefectiva, toda vez que el recurso de protección puede interponerse sin perjuicio de otras acciones que se hagan valer ante la autoridad o los tribunales correspondientes, por lo que para efectos de la protección de derechos fundamentales, este recurso pasó a ser un verdadero equivalente o sustituto de la jurisdicción común ${ }^{8}$, lo que en la práctica significó que toda afectación a un derecho constitucional pudiese ser impugnada o cuestionada, a un mismo tempo, ante la jurisdicción ordinaria. Así, hoy el recurso de protección es comprendido solo como una acción cautelar, cuyo propósito es preservar o retornar al statu quo vigente al momento de la afectación del derecho, más que resolver sobre el fondo del derecho posiblemente transgredido, por lo que ciertamente, tal recurso no resulta el mecanismo idóneo para otorgar adecuada protección a los derechos fundamentales de los trabajadores?.

Además de lo anterior, y como acertadamente señala Cristian Melis ${ }^{10}$, el recurso de protección solamente protege bienes jurídicos patrimoniales, las demás dimensiones de la personalidad del trabajador (honra, vida privada, integridad psíquica, u otros), prácticamente no gozaban de protección, por lo que previo a este nuevo procedimiento, el recurso de protección servía más para limitar las atribuciones de la Dirección del Trabajo que para proteger las garantías constitucionales de los trabajadores.

Así, mediante la incorporación del procedimiento de tutela laboral por la Ley $\mathrm{N}^{\circ}$ 20.087, el legislador ha agregado a nuestro ordenamiento jurídico un procedimiento ca-

\footnotetext{
6 Por "ciudadanía en la empresa" entendemos la definición dada por Eduardo Caamaño: "la aceptación de que el espacio privado en el que se desarrollan las relaciones laborales -la empresa- no es un ámbito marginado del respeto, protección y ejercicio de aquellas garantías propias de todo ser humano por el solo hecho de ser tal". CaAMAÑo, Eduardo. "La ley de subcontratación y la tutela de los derechos fundamentales", en: Ius et Praxis, año 13 n² 2, Talca, Chile, 2007, p. 171.

7 Constitución Política de la República, Artículo 6 inciso segundo: "Los preceptos de esta Constitución obligan tanto a los titulares o integrantes de dichos órganios como a toda persona, institución o grupo".

8 GOMEZ, Gastón. Derechos Fundamentales y Recurso de Protección. Santiago, Chile: Ediciones Universidad Diego Portales, 2005, p. 24.

9 A mayor abundamiento, ya en el año 2005, el profesor Gastón Gómez concluía que existía una "necesidad institucional de crear una nueva acción para la tutela de derechos fundamentales". Ibid.

10 MELIS, Christian. Los derechos fundamentales de los trabajadores como limites a los poderes empresariales. Santiago, Chile: LegalPublishing, 2010, p. 29.
} 
paz de hacer eficaz la protección a los derechos fundamentales de los trabajadores ${ }^{11}$ en el peculiar contexto de disparidad de fuerzas propio de la relación laboral. De esta forma, este procedimiento se convierte en la herramienta idónea para la aplicación directa de la Constitución en materia laboral, tanto por dar eficacia a la supremacía constitucional en el seno de las relaciones de trabajo, como por garantizar la eficacia horizontal inmediata de los derechos fundamentales de los trabajadores ${ }^{12}$.

Los derechos fundamentales que son objeto del procedimiento de tutela se encuentran establecidos en el artículo 485 del Código del Trabajo ${ }^{13}$ : derecho a la vida; derecho a la integridad física; derecho a la intimidad y respeto a la vida privada; derecho al honor; derecho a la inviolabilidad de toda forma de comunicación privada; derecho a la libertad de conciencia, la manifestación de las creencias y el libre ejercicio de todos los cultos; libertad de expresión, opinión e información sin censura previa y la libertad de trabajo y contratación laboral. Tales derechos se considerarán vulnerados cuando el ejercicio de las facultades que la ley reconoce al empleador limita el pleno ejercicio de aquellas sin justificación suficiente, en forma arbitraria o desproporcionada, o sin respeto a su contenido esencial.

Sin embargo, si bien los artículos 485 y siguientes del Código del Trabajo detallan ampliamente el procedimiento de la acción de tutela laboral, en sus artículos encontramos una omisión que esencialmente motiva el presente trabajo: quién debe responder por la vulneración de estos derechos, pregunta que se hace más compleja cuando la vulneración de derechos ocurre en una relación laboral de carácter triangular, como es el caso de la subcontratación. En base a lo anterior, se hace imperativo el tener absoluta claridad respecto a quienes tienen legitimación pasiva respecto a una acción de tutela laboral, especialmente en virtud del creciente aumento de este tipo de acciones y en virtud de la modificación propuesta por la Ley $\mathrm{N}^{\circ} 20.260$, norma que estableció que las demandas de tutela laboral podían ser interpuestas conjuntamente junto a las demandas por despido injustificado, lo cual si bien es un avance en lo que a economía procesal se refiere, ha hecho que los juzgados de letras del trabajo conozcan causas en que la afectación a un derecho fundamental sea cuestionable, por decir lo menos ${ }^{14}$.

11 Al respecto, nos parece que la doctrina nacional no ha sido lo suficientemente precisa respecto al significado de un derecho fundamental, imprecisión que ha hecho que en muchas ocasiones cualquier vulneración a un derecho se considere como una violación a un derecho fundamental. Por lo anterior, y para efectos del presente trabajo, entenderemos por derecho fundamental la definición dada por Antonio Pérez Luño: "conjunto de facultades e instituciones que concretan las exigencias de dignidad, libertad, igualdad y seguridad humanas, en cuanto expresión de la dignidad de los seres humanos -considerados tanto en su aspecto individual como comunitario-, en un contexto histórico determinado, las cuales deben ser aseguradas, respetadas, promovidas y garantizadas por los ordenamientos jurídicos a nivel nacional, supranacional e internacional, formando un verdadero subsistema dentro de estos". Para más información, ver PÉREZ LUÑo, Antonio. Los derechos humanos. Significación, estatuto jurídico y sistema. Universidad de Sevilla. 1999.

12 Silva, Luis. "Supremacía Constitucional y Tutela Laboral", en: Revista de Derecho, vol. XXIV, $\mathrm{n}^{\circ}$ 1, Valdivia, Chile, julio 2011 , p. 35.

13 A los cuales debe agregarse el derecho a la libertad sindical, como ordena expresamente el artículo 292 del Código del Trabajo.

14 En este sentido, una sentencia del Juzgado de Letras del Trabajo de Valparaíso resalta en forma muy clara lo infundadas de algunas demandas de tutela laboral, las cuales pueden resultar constitutivas de despido injustificado, pero en ningún caso vulneratorias de derechos fundamentales: "en todo despido hay cierta discriminación propia de excluir a uno o varios trabajadores de acuerdo con la facultad de administración del empleador, sin perjuicio de la necesidad y justificación de tal medida". Al 
Así, para comenzar a dilucidar la responsabilidad de la empresa principal en esta materia, analizaremos la obligación que el artículo 183-B del Código del Trabajo le impone a la empresa principal, para así poder contrastarla con la supuesta obligación de la empresa principal de responder de la vulneración de los derechos fundamentales de los trabajadores de la empresa contratista.

\section{OBLIGACIÓN DE LA EMPRESA PRINCIPAL DE RESPONDER DE LAS OBLIGACIONES LABORALES Y PREVISIONALES DE DAR DEL CONTRATISTA}

\section{El Artículo 183-B del Código del Trabajo establece que:}

“Art. 183-B. La empresa principal será solidariamente responsable de las obligaciones laborales y previsionales de dar que afecten a los contratistas en favor de los trabajadores de estos, incluidas las eventuales indemnizaciones legales que correspondan por término de la relación laboral. Tal responsabilidad estará limitada al riempo o período durante el cual el o los trabajadores prestaron servicios en régimen de subcontratación para la empresa principal".

Lo anterior es una verdadera excepción al régimen de responsabilidad en materia laboral, toda vez que señala que la empresa principal deberá responder, inclusive en forma solidaria, de las obligaciones laborales y previsionales de trabajadores que no son suyos.

Dicha excepción fue justificada en su época en virtud de que con anterioridad a la Ley $\mathrm{N}^{\circ} 20.123$, el Código del Trabajo, en sus artículos 64 y 64 bis $^{15}$, regulaba la existencia de las empresas contratistas y el grado de responsabilidad que estas tenían frente a las obligaciones laborales y previsionales de los trabajadores de empresas contratistas y subcontratistas, normativa que no daba solución a todos los problemas que se presentaban en las relaciones laborales, como la delimitación del trabajo en régimen de subcontratación, las responsabilidades en materia de higiene y seguridad, el deber de vigilancia, etc. ${ }^{16}$.

A su vez, tal excepción a las reglas generales de la responsabilidad laboral resultaba necesaria para poder reconocer, como lo hace implícitamente la Ley $\mathrm{N}^{\circ} 20.123$, y tal cual como ocurrió en la legislación comparada, que el fenómeno económico de la externalización constituye una forma válida de toda empresa para organizar su funcionamiento ${ }^{17}$, alejando así, las suspicacias que dicha modalidad generaba en la doctrina laboral, que intuía que esta se trataba más bien de una simulación laboral que de un verdadero mecanismo de organización de la producción.

\footnotetext{
respecto, ver "Berríos con Compañía de Servicios de Movilización". 19 de febrero de 2010. T-53-2009. Juzgado de Letras del Trabajo de Valparaiso.

15 Ambos artículos fueron derogados por el artículo primero de la Ley 20.123.

16 Albornoz, Marcelo; ALVIZ, Christian; PÉREZ, Enrique. Subcontratación Laboral y Servicios Transitorios. Santiago, Chile: Editorial LexisNexis, 2007, p. 2.

17 CASTELlO, Alejandro. "La Subcontratación y las Relaciones de Trabajo en Uruguay", en: Revista Latinoamericana de Derecho Social $\mathrm{n}^{\circ}$ 9, julio-diciembre 2009, Montevideo, Uruguay, p. 61.
} 
Sin embargo, independiente de las consideraciones prácticas que motivaron el establecimiento de esta excepción a la responsabilidad laboral, bien vale preguntarse cuál es el fundamento jurídico por el que la empresa principal debe hacerse responsable de las obligaciones laborales y previsionales de los trabajadores de la empresa contratista ${ }^{18}$, de forma de tener claridad de por qué tales requisitos o fundamentos no se cumplen respecto a la supuesta obligación que se le generaría a la empresa principal por la vulneración a los derechos fundamentales de los trabajadores de la empresa contratista. Al respecto, creemos que la excepción en cuestión se justifica en virtud de tres razones: a) Ajenidad; b) Derecho de Información y Retención; c) Principio protector.

\section{a) Ajenidad}

Por ajenidad entendemos que el trabajador presta sus servicios por cuenta de su empleador, quien asume los riesgos del trabajo y se hace dueño de los frutos que este genera ${ }^{19}$. En el caso de la subcontratación, la empresa contratista se mantiene como empleador del trabajador, pero los frutos del trabajo se radican en la empresa principal.

En atención a este importante rasgo que caracteriza a la subcontratación, la responsabilidad de la empresa principal se justifica en que no sería justo que esta se viese exenta de responder de las obligaciones generadas por un trabajador que ha aportado su trabajo para el desarrollo de la empresa principal, toda vez que su riqueza proviene en parte del trabajo de dicho trabajador, ya que es la combinación de capital más trabajo lo que la genera, por lo que si es que la empresa principal va a gozar de los beneficios del trabajo de un trabajador sobre el cual no tiene un vínculo de subordinación, lo justo es que también deba responder en los casos en que dicho trabajo no se ajusta a los estándares mínimos que nuestra legislación laboral dispone ${ }^{20}$.

\footnotetext{
18 Al respecto, nos llama profundamente la atención el poco énfasis que la doctrina le ha dado a los fundamentos de la subcontratación, tomando en consideración que dicha modalidad viene a romper el efecto relativo de los contratos. En relación a ello, consideramos una lectura obligada lo planteado por el profesor Palavecino respecto al "problema del fundamento" de la subcontratación. Para mayor información, ver PaLAvecino, Claudio. Subcontratación Régimen Jurídico del Trabajo Subcontratado y del Suministro de Personal. Santiago, Chile: Editorial Jurídica de Chile 2006.

19 Alonso OleA, Manuel. "Trabajo libre y trabajo dependiente", en: Estudios sobre derecho individual de trabajo en homenaje al Profesor Mario L. Deveali. Buenos Aires, Argentina: Editorial Heliasta, 1979, pp. 156-157.

20 Al respecto, el profesor Palavecino desestima este fundamento, al sostener que semejante interpretación desatiende el carácter oneroso conmutativo del contrato de obra o de servicio celebrado entre el empresario principal y el contratista o, en su caso, del subcontrato celebrado entre el contratista y subcontratista, toda vez que la actividad laboral de los trabajadores integra el objeto de la obligación del contratista y, a su vez, forma parte de la causa de la obligación del empresario principal de pagar, a cambio, un determinado precio, el cual se mira como equivalente, por lo que si es que el empresario principal ya se obligó a pagar un precio justo por aquella prestación, no puede ser este el fundamento que justifique la asunción de obligaciones adicionales no consentidas. Discrepamos con la postura del profesor, en virtud de que consideramos correcto que la obligación de la empresa principal de pagar las obligaciones laborales de la empresa contratista o subcontratista no forme parte del precio, toda vez que la responsabilidad de la empresa principal en esta materia es de carácter extracontractual, al escapar del objeto del contrato de obra o servicio entre empresa principal y contratista o subcontratista, tal y como sucedería si es que el mandante dañase a un edificio aledaño en la ejecución del contrato. La diferencia entre estos casos es que mientras la empresa principal no obtiene beneficio alguno del edificio aledaño, sí obtiene beneficios de los servicios de los trabajadores de la empresa contratista, razón por la cual resulta justo que la empresa principal sea susceptible de responder en caso de un incumplimiento de la empresa contratista y subcontratista, teniendo presente que la empresa principal siempre podrá repetir lo pagado en contra del empleador del trabajador. Para mayor información respecto a la postura del profesor, ver PALAVECINO, Claudio, op. cit. (n. 19), pp. 56 y ss.
} 
Por lo demás, dicho raciocinio es el mismo utilizado por la Excma. Corte Suprema ${ }^{21}$ para justificar la responsabilidad subsidiaria de la empresa principal en las hipótesis contempladas en los derogados artículos 64 y 64 bis del Código del Trabajo.

A su vez, no olvidar que si bien el elemento que determina una relación laboral es la subordinación, la ajenidad es el "justificativo jurídico-ético de la subordinación"22 y lo que fundamenta la facultad de mando del empleador, antecedente sumamente importante para comprender la responsabilidad que nuestra legislación le impone a la empresa principal respecto a trabajadores de otro empleador.

Por estas razones, pareciese ser bastante desproporcionado que la empresa principal gozase de todos los frutos del trabajo del trabajador sin que se le otorgase una carga equivalente al rédito que la empresa principal espera obtener del trabajo del trabajador, por lo que en atención al factor ajenidad, la responsabilidad que la legislación le otorga a la empresa principal pareciese estar debidamente justificada.

\section{b) Derecho de información y retención}

Si bien la característica de ajenidad resulta sumamente importante, tampoco sería justo atribuirle igual niveles de responsabilidad a ambas organizaciones (empresa contratista y empresa principal), toda vez que nuestra legislación laboral es bastante clara en señalar que los trabajadores de la empresa contratista solamente tienen un vínculo de subordinación con tal entidad ${ }^{23}$.

A su vez, tampoco sería eficiente el que la empresa principal no contase con los medios para ver atenuada su responsabilidad, toda vez que de no existir tales medios, la empresa principal no tendría ningún estímulo para fomentar el cumplimiento de las obligaciones laborales y previsionales de los trabajadores contratistas, objetivo principal de nuestra legislación laboral.

Por lo anteriormente expuesto, el artículo 183-C y 183-D del Código del Trabajo le otorgan a la empresa principal dos herramientas con las cuales puede ver atenuada su responsabilidad, pudiendo responder solamente en forma subsidiaria: el derecho de información y el derecho de retención.

El derecho de información, según lo establece el artículo 183-C del Código del Trabajo, es: "el derecho que tiene la empresa principal de ser informada sobre el monto y estado de cumplimiento de las obligaciones laborales y previsionales, tanto de los trabajadores del

\footnotetext{
21 "Yazmín Sabat Greyet con Vitrogen S.A. y otro". 22 de junio de 2009, Rol 2161-2009, Excma. Corte Suprema. considerando sexto: "Que, tal como ha dicho esta Corte anteriormente, la especial calidad prevista en el artículo 64 del Código del Trabajo, y a la cual dicha norma le atribuye como consecuencia, que el dueño de la obra debe responder, al igual que el empleador directo, de las prestaciones laborales de los trabajadores del contratista, se fundamenta en la existencia de una obra, cuyo dueño la entrega a un tercero, para que este realice actividades respecto de ella, que aquel no puede o no quiere hacer por sí mismo. Así, el dueño de la obra respalda y garantiza lo que hace el tercero, en lo que a los conceptos aludidos se trata, porque se beneficia de lo que aquel hacen pudiendo y debiendo, para ello, fiscalizarlo."

22 ERmida, Oscar y Hernández, Oscar. "Crítica de la Subordinación", en: Revista Laboral Chilena, abril 2002, Santiago, Chile, p. 77.

23 Así, los profesores Lizama y Ugarte resumen la importancia de la subordinación en materia de relaciones laborales triangulares en que: "en una relación triangular de trabajo, si el trabajador está subordinado a la empresa externa, se encuentra en un régimen de subcontratación, y si está subordinado a la empresa principal, está en una situación de suministro". LIZAMA, Luis y UGARTE, José Luis. Subcontratación y Suministro de Trabajadores. Santiago, Chile: LegalPublishing, 2009, p. 14.
} 
contratista como del subcontratista". Ahora, en caso de que las obligaciones a las que se refiere el citado artículo no hayan sido satisfechas en su totalidad, la empresa principal puede utilizar el derecho de retención establecido en el artículo 183-D del Código del Trabajo, norma que dispone que: "la empresa principal podrá retener los montos de cualquier obligación pendiente que posea la empresa principal a favor de la empresa contratista, debiendo pagar con dicha retención al trabajador o institución previsional acreedora”.

Así, la responsabilidad de la empresa principal se fundamenta en que la ley le otorga a la empresa principal mecanismos de control respecto de los contratistas y subcontratistas, para así incentivar el sistema de autocontrol del cumplimiento de la legislación laboral. Por tanto, resulta plenamente justificable que la empresa principal deba responder, solidariamente inclusive, de las obligaciones laborales y previsionales de dar de los trabajadores de la empresa contratista, toda vez que es el negligente actuar de la empresa principal el que la lleva a responder solidariamente ${ }^{24}$, justificándose la responsabilidad subsidiaria de la empresa principal en atención al beneficio que los trabajadores de la empresa principal obtienen de la empresa contratista, y en virtud del principio protector.

\section{c) Principio protector}

El principio protector es un principio fundamental en materia laboral, y el criterio que orienta al derecho del trabajo, por el cual, en lugar de buscar un propósito de igualdad para las partes, se responde al objetivo de establecer un amparo preferente a una de ellas: el trabajador $^{25}$. Así, es este principio el que fundamenta la existencia de un mayor juicio de reproche sobre la empresa principal que sobre el trabajador, al que la legislación laboral busca proteger. A mayor abundamiento, la aplicación irrestricta de este principio en el ámbito de la subcontratación laboral se fundamenta en dos situaciones en las cuales el empleador presenta ventajas sobre el trabajador, desde el punto de vista jurídico.

La primera es que entre la empresa principal y la empresa contratista existe plena libertad contractual, lo que no sucede en el caso del trabajador con la empresa contratista. Así, en la eventualidad de un incumplimiento de obligaciones laborales, nuestra legislación establece un juicio de reproche mayor sobre la empresa principal, toda vez que esta fue negligente en su actuar, no solamente al verificar los antecedentes económicos de la empresa con la cual contrató, sino que también porque la empresa principal tiene una posición jurídica prevalente respecto de la empresa contratista, lo que se ve reforzado por la atribución legal de los derechos de información y retención ${ }^{26}$.

La segunda ventaja es que la empresa principal es más apta para sustentar un eventual pago de una obligación ${ }^{27}$. En efecto, la hipótesis de que la empresa principal posee mayores recursos económicos que el trabajador, y, por lo tanto, le es menos inconveniente pagar, es

\footnotetext{
24 Ibid., p. 59.

25 PLÁ, Américo. Los Principios del Derecho del Trabajo. Buenos Aires, Argentina: Ediciones Depalma, 1978, p. 61.

26 LIZAMA, Luis y UGARTE, José Luis, op. cit. (n. 24), p. 59.

27 En igual sentido, Alejandro Castelló señala que se justifica el traslado de riesgos económicos y laborales a la empresa principal, toda vez que esta "se presume más fuerte y solvente". CASTELLÓ, Alejandro, op. cit. (n. 18), p. 82.
} 
una presunción prácticamente de derecho sobre la cual se funda el principio protector, y que justificaría la responsabilidad de la empresa principal en materia de subcontratación.

\section{OBLIGACION DE LA EMPRESA PRINCIPAL DE RESPONDER POR UNA VULNERACIÓN A LOS DERECHOS FUNDAMENTALES DE LOS TRABAJADORES DE LA EMPRESA CONTRATISTA}

Ya analizadas las razones por las cuales la empresa principal está obligada a responder, solidaria o subsidiariamente, de las obligaciones laborales y previsionales de la empresa contratista, y los fundamentos de dicha responsabilidad, cabe preguntarnos si es que efectivamente la empresa principal debe responder ante una vulneración de derechos fundamentales de los trabajadores de la empresa contratista.

A este respecto, primero debemos analizar si es que los términos del artículo 183-B del Código del Trabajo alcanzan inclusive a la vulneración de los derechos fundamentales de los trabajadores. De concluir que dicho artículo tiene tal alcance, se estaría afirmando que la obligación de no vulnerar los derechos fundamentales de los trabajadores constituye una de las obligaciones laborales y previsionales de dar a las cuales hace referencia el artículo 183-B del Código del Trabajo, o que es parte de las indemnizaciones legales que el trabajador tiene derecho a recibir, como también establece el mismo artículo. Ambas situaciones no son efectivas, como procederemos a justificar.

Respecto al alcance de las obligaciones de dar con carácter laboral y previsional, la opinión prácticamente unánime de la doctrina ${ }^{28} \mathrm{y}$ jurisprudencia es que dichas obligaciones se refieren a: i) remuneraciones; ii) asignaciones en dinero; iii) cotizaciones previsionales; iv) indemnizaciones legales por término del contrato de trabajo. Lo anterior es corroborado por el dictamen $\mathrm{N}^{\circ}$ 0141/05 de la Dirección del Trabajo, el cual señala que: "armonizando todo lo expuesto, resulta dable afirmar que la responsabilidad solidaria que asiste a la empresa principal y al contratista, por las obligaciones laborales de dar a favor de los trabajadores del contratista o subcontratista, según corresponda, alcanzará todas aquellas obligaciones que, derivando de los contratos individuales o colectivo de trabajo o del Código del Trabajo y sus leyes complementarias, consistan en el pago de una suma de dinero determinada".

¿Es la sanción que se establece en materia de tutela laboral una obligación de dar? Indudablemente no. El artículo 485 es claro en establecer que los derechos fundamentales tutelados son prohibiciones, en las cuales se le prohíbe al agente realizar determinadas acciones: no discriminar, no violar la libertad sindical, no vulnerar la integridad física de un trabajador, etc. Ahora, es cierto que toda vulneración de una obligación de no hacer genera una obligación positiva de resarcir el perjuicio causado, sea una obligación de dar (ej: una compensación económica), o de hacer ${ }^{29}$ (reparar el daño causado). Eso no desnaturaliza el concepto mismo de una obligación de no hacer, por lo que mal podría usarse el argumento

28 LizAMA, Luis y UGARTE, José Luis, op. cit. (n. 24), p. 39.

29 FUEYO, Fernando. Incumplimiento de las obligaciones $-3^{\mathrm{a}}$ edición-. Actualizada por el profesor Gonzalo Figueroa Yáñez. Santiago, Chile: Editorial Jurídica de Chile, 2004, p. 290. 
de que la obligación de dar de la empresa principal es la que se genera con posterioridad a la vulneración de la garantía constitucional.

Ahora, sería posible pensar que el anterior argumento es falible en virtud de que en materia de subcontratación, el Código del Trabajo establece obligaciones de no hacer sobre las cuales la empresa principal sí se hace responsable, como en el caso de los accidentes del trabajo $^{30}$. Sin embargo, la responsabilidad que tiene la empresa principal respecto a los accidentes del trabajo no deriva del artículo 183-B del Código del Trabajo, sino que del Artículo $183-\mathrm{E}$, el cual señala:

"Art. 183-E. Sin perjuicio de las obligaciones de la empresa principal, contratista y subcontratista respecto de sus propios trabajadores en virtud de lo dispuesto en el artículo 184, la empresa principal deberá adoptar las medidas necesarias para proteger eficazmente la vida y salud de todos los trabajadores que laboran en su obra, empresa o faena, cualquiera sea su dependencia, en conformidad a lo dispuesto en el artículo 66 bis de la ley No 16.744 y el artículo $3^{\circ}$ del decreto supremo No 594, de 1999, del Ministerio de Salud".

Es decir, existe una mención expresa de nuestro Código del Trabajo que le impone a la empresa principal la obligación de responder en caso de estos funestos sucesos, mención que existe precisamente porque de no existir dicha mención, al tenor del artículo 183-B, la empresa principal no sería responsable.

En virtud de lo señalado anteriormente, es que el argumento más utilizado para hacer responsable a la empresa principal en el procedimiento de tutela laboral es señalar que el pago al cual obliga este proceso constituye una indemnización por término de la relación laboral, en los casos de despido vulneratorio de derechos fundamentales o de renuncia en virtud de tales vulneraciones. Sin embargo, una interpretación rigorosa del artículo 183-B del Código del Trabajo deja en evidencia que lo que este dispone es que la empresa principal puede ser condenada a pagar las indemnizaciones legales con ocasión del término de un contrato de trabajo, sin referirse a las sanciones por vulneración de derechos, omisión realizada precisamente porque las indemnizaciones por término del contrato de trabajo y las sanciones por vulneración de derechos fundamentales tienen una naturaleza jurídica distinta.

La indemnización legal por término del contrato de trabajo es una suma de dinero que debe pagarse al trabajador en los casos en que el empleador lo despide por alguna de las causales establecidas en el artículo 161 del Código del Trabajo, si es que el contrato de trabajo ha estado vigente durante un año o más. Dicho pago no tiene la naturaleza jurídica de una sanción para el empleador, toda vez que este es un mecanismo contemplado en la legislación laboral para atenuar los perjudiciales efectos que tiene para el trabajador perder su

\footnotetext{
30 Si bien este es un ámbito que excede el presente trabajo, es importante hacer notar que es una antigua discusión doctrinaria si es que la obligación del empleador en materia de accidentes del trabajo es una obligación de hacer: adoptar las medidas necesarias para proteger eficazmente la vida de los trabajados; o de no hacer: no realizar acciones que dañen al trabajador. Al respecto, si bien consideramos la obligación del empleador en materia de accidentes del trabajo es una obligación de hacer, debemos hacer notar que aun considerando tal obligación como una de no hacer, la empresa principal no estaría obligada a responder de la vulneración a los derechos fundamentales de los trabajadores.
} 
fuente de ingresos, no siendo el comportamiento del empleador la razón por la cual el trabajador tiene el derecho de recibir este pago.

Por otra parte, y a diferencia de la indemnización señalada anteriormente, el pago que contempla el artículo 489 del Código del Trabajo es una sanción para aquellos sujetos que vulneran ciertas garantías constitucionales del trabajador, en donde el pago opera como una compensación que se le hace al trabajador por el menoscabo sufrido y una sanción al empleador por su conducta, independientemente de que en ciertos casos dicha sanción proceda en conjunto con una indemnización por término de contrato de trabajo.

En resumen, del tenor literal del artículo 183-B del Código del Trabajo, podemos colegir que la empresa principal no tiene responsabilidad alguna por la vulneración de los derechos fundamentales de la empresa contratista, pues este artículo no contempla la hipótesis de responsabilidad que establece el procedimiento de tutela de derechos fundamentales.

\section{FACULTADES DE LA EMPRESA PRINCIPAL DE IMPEDIR O PREVENIR LA VULNERACIÓN DE UN DERECHO FUNDAMENTAL DE UN TRABAJADOR}

Además de lo anterior, es importante destacar que los fundamentos que justifican que la empresa principal responda por las obligaciones laborales y previsionales de dar de la empresa contratista, no se aplican para los supuestos de hecho del procedimiento de tutela de derechos fundamentales.

Así, y como punto de partida, debemos plantearnos si es que nuestra legislación le atribuye a la empresa principal facultades suficientes como para impedir una vulneración a los derechos fundamentales de los trabajadores de la empresa contratista, ya que es importante recordar que una de las razones por las cuales la empresa principal se ve obligada a responder de las obligaciones de los trabajadores de la empresa contratista es por el actuar negligente de la empresa principal, tanto por no utilizar su derecho de información y retención, como por el contratar con una empresa que no otorgó las garantías necesarias para asegurar el cumplimiento de las obligaciones laborales de los trabajadores ${ }^{31}$. Por tanto, de ser efectivo que la empresa principal no cuenta con las facultades necesarias para impedir la vulneración de un derecho fundamental, los únicos fundamentos por los cuales podría sostenerse que la empresa principal debe responder por las vulneraciones a los derechos fundamentales de la empresa contratista serían la ajenidad y el principio protector en materia laboral.

El derecho de información que establece el Código del Trabajo se ejerce a través de certificados que acreditan que las remuneraciones y cotizaciones previsionales de los trabajadores se encuentran satisfechas ${ }^{32}$. Esto queda en evidencia en el dictamen $N^{\circ} 3267 / 069$

\footnotetext{
31 Téngase en consideración que las facultades económicas de una empresa, y la posibilidad de que esta se vea imposibilitada de cumplir con las obligaciones laborales de sus trabajadores, son situaciones objetivas, a diferencia de la posibilidad de que una empresa vulnere los derechos fundamentales de sus trabajadores, situación de por sí subjetiva, y por lo tanto, imposible de prever por un tercero en forma previa al acaecimiento de los hechos.

32 Al respecto, el Decreto Supremo No 319 del Ministerio del Trabajo y Previsión Social, de fecha 13 de diciembre de 2006, aprueba el reglamento del artículo 183-C del Código del Trabajo sobre acreditación de cumplimiento de obligaciones laborales y previsionales. Dicho reglamento señala expresamente que el derecho de información de la empresa principal se ejercerá mediante la acreditación del monto y estado de cumplimiento de las obligaciones laborales y previsionales de la empresa contra-
} 
de la Dirección del Trabajo, el cual establece la forma en la cual la empresa principal da cumplimiento a su derecho de información: "para acreditar el monto y estado de las obligaciones laborales y previsionales de los trabajadores del contratista en conformidad al inciso $2^{\circ}$ del artículo 183-C del Código del Trabajo, resulta suficiente la presentación de un certificado emitido por la Inspección del Trabajo respectiva o por las entidades o instituciones legalmente competentes". En igual sentido se han pronunciado los fallos de los Juzgados de Letras del Trabajo.

En virtud de que la empresa principal ejerce plenamente su derecho de información mediante la solicitud de comprobantes de pago de remuneraciones y cotizaciones previsionales $^{33}$, pareciese ser que el ejercicio de este derecho poco podría influenciar en la vulneración de un derecho fundamental, pues tal vulneración no tiene relación con remuneraciones y cotizaciones previsionales. Sin embargo, aun suponiendo que la exigibilidad del legislador fuese mayor que la efectivamente exigida, y que se estableciese que el derecho de información debe ser ejercido para detectar cualquier vulneración a derechos fundamentales, aun su más pleno ejercicio no aseguraría tal propósito, toda vez que este derecho, aun en su máxima expresión, resulta absolutamente inútil para detectar violaciones a garantías constitucionales. Para clarificar, señalaremos ejemplos emanados de nuestra propia judicatura.

Para el primer ejemplo, tomemos el caso del juicio caratulado "Sindicato de Trabajadores Empresa Express de Santiago Uno S.A. con Empresa Express de Santiago Uno S.A." ${ }^{4}$, el cual versa sobre el derecho a la dignidad, libertad e integridad psíquica de los choferes afiliados al sindicato, y en el cual la empresa fue condenada al pago de 60 Unidades Tributarias Mensuales, al comprobarse quie la empresa no otorgaba a sus trabajadores el tiempo necesario para colación y descanso, al punto que muchas veces no contaban ni siquiera con el tiempo y espacio para orinar, debiendo de hacerlo desde los buses que manejaban o en una botella plástica preparada para tal efecto.

En este caso, en el evento de haber existido una relación de subcontratación: ¿podría la empresa principal haber prevenido tal vulneración? Creemos que no, ya que como el derecho que tiene la empresa principal es el de informarse, no el de planificar la actividad empresarial del contratista, aun en estos casos, en donde la vulneración es sumamente evidente y posible de detectar mediante parámetros objetivos, tales como mecanismos de control de conducción o áreas habilitadas para el descanso, la empresa principal solo se vería informada

tista o subcontratista, estableciendo las condiciones en las cuales otros organismos, distintos a la Dirección del Trabajo, pueden dar fe de dicha situación.

33 Igual análisis hace la doctrina uruguaya respecto a su ley de subcontratación, la cual es sumamente parecida con la nuestra. $\mathrm{Al}$ respecto, Alejandro Castelló señala que: "en cuanto al contenido de la obligación de informar, las leyes prevén que contemple el monto del salario y las condiciones de empleo, debiéndose entender por estas últimas a variables como el tiempo de trabajo, la categoría y la duración del contrato, razón por la cual el artículo 4 de la ley 18.251 otorga a la empresa principal el derecho a exigir la exhibición de una serie de documentos que son demostrativos del estado de cumplimiento de las obligaciones laborales y previsionales". CASTELLO, Alejandro, op. cit. (n. 18), p. 80.

34 "Sindicato de Trabajadores Empresa Express de Santiago Uno S.A. con Empresa Express de Santiago Uno S.A.". 18 de agosto de 2010. T-86-2010. $2^{\circ}$ Juzgado de Letras del Trabajo de Santiago. 
a posteriori ${ }^{35}$ de dicha vulneración, ya que con anterioridad a ello no existe ningún derecho fundamental vulnerado del cual la empresa principal podría informarse.

A mayor abundamiento, en el caso aquí planteado se genera otro problema sumamente importante, como es que en estos casos el empleador no contará con el derecho de retención, mecanismo que le otorga el sustento práctico al derecho de información. Lo anterior por una razón muy sencilla: los tribunales de justicia son los únicos encargados de poder determinar que un derecho fundamental fue vulnerado ${ }^{36}$, por lo que aun en los casos en los cuales la afectación a derechos fundamentales sea evidente, como en el caso en cuestión, nuestro ordenamiento jurídico no le otorga al empleador la facultad de juzgar por sí mismo que una situación constituye una vulneración de derechos fundamentales. Es por ello que la retención se limita a situaciones fácticas, no jurídicas, como si es que a un trabajador se le pagaron sus sueldos y/o cotizaciones previsionales ${ }^{37}$.

Para el segundo ejemplo, tomemos el caso de la "Dirección Regional del Trabajo con Envases Exporta" 38 , juicio que trató sobre una acción de tutela de derechos fundamentales por discriminación del empleador contra uno de sus trabajadores. En este caso, Envases Exporta fue condenado a 50 Unidades Tributarias Mensuales, en virtud de que se falló que el empleador vulneró el derecho a la no discriminación por raza de la trabajadora, al existir indicios suficientes para declarar que lo afirmado por los numerosos testigos del juicio era verídico, en el sentido que el empleador en reiteradas ocasiones se refería a la trabajadora como "esta mapuche" o "esta indígena", y en peores términos como "esta mapuche no sirve para nada, no se apura con lo que le pido" o "indígena que no me escucha que no me toma atención, tan amargada que es".

Con los antecedentes presentes, conviene preguntarse: de haber existido una relación laboral de subcontratación ¿podría haber hecho algo la empresa para evitar tal discriminación? En efecto, y a diferencia del ejemplo anterior, esta vulneración de derechos no es posible de identificar mediante parámetros objetivos, por lo que la única forma que la empresa

\footnotetext{
35 Conviene hacer presente que las vulneraciones a los derechos fundamentales no se encuentran establecidas expresamente en los manuales operacionales o instructivos de funcionamiento de cada empresa, sino que más bien resultan una práctica consuetudinaria que escapa a lo formalmente expresado en los reglamentos y estatutos internos, de tal forma que no resulta sensato plantear que mediante esta vía, la empresa principal podría enterarse, previo a las acciones vulneratorias, de algún procedimiento que atentase contra las garantías constitucionales de los trabajadores. Lo anterior resulta un claro ejemplo de la importancia del principio de primacía de la realidad en materia laboral.

36 En efecto, el mandato constitucional establecido en el artículo 19 No 3 inciso de la Constitución Política de la República es sumamente claro al establecer que: "Nadie podrá ser juzgado por comisiones especiales, sino por el tribunal que señalare la ley y que se hallare establecido por esta con anterioridad a la perpetración del hecho".

37 Al respecto, conviene tener presente que la Dirección del Trabajo, en dictamen No 1280/20, ha señalado que: "la circunstancia de existir tal controversia origina una situación cuyo conocimiento escapa a la competencia de este Servicio, toda vez que su resolución requiere de prueba, ponderación de la misma y la sujeción al procedimiento establecido por la ley, todo lo cual debe verificarse ante el ente jurisdiccional correspondiente". De igual opinión ha sido la Excma. Corte Suprema desde ya hace muchos años, como lo demuestra el siguiente fallo del 15 de junio del año 1989, en causa "Sociedad Benefactora Colonia Dignidad con Dirección del Trabajo": "Las inspecciones del trabajo solo pueden constatar hechos, no pueden convertirse en una instancia de resolución de controversias". En vista de que ni siquiera la Dirección del Trabajo cuenta con facultades jurisdiccionales para declarar este tipo de situaciones, menos podría tenerla un particular, por más evidente que dicha vulneración pueda parecer".

38 “Dirección Regional del Trabajo con Envases Exporta". 19 de marzo de 2011. T-403-2010. 20 Juzgado de Letras del Trabajo de Santiago.
} 
principal pudo haber impedido tales actos sería si es que esta tuviese representantes que interviniesen o controlasen la relación laboral entre el empleador el trabajador de la empresa contratista, lo cual es completamente ajeno al espíritu y tenor literal de la Ley $\mathrm{N}^{0} 20.123$, norma que reconoce y acepta como válido el mecanismo de descentralización productiva llamado subcontratación, cuya esencia radica en la desconexión de la empresa principal de las relacionales laborales entre la empresa contratista y sus trabajadores. Precisamente, el derecho de información que establece la Ley $\mathrm{N}^{\circ} 20.123$ incentiva a la empresa principal para que dicha desconexión no sea absoluta, pero no al punto de entrometerse en el diario convivir de empleador y trabajador, toda vez que de exigir la ley tal parámetro de conducta no tendría ningún sentido el subcontratar, siendo más fácil, útil y conveniente para la empresa principal el contratar trabajadores por cuenta propia.

En consideración a lo anterior, cabe preguntarnos si es que en nuestra legislación laboral la ajenidad resulta tan relevante o el principio protector rige de tal manera, que puede hacerse responsable a un agente que no tuvo participación en los hechos ni pudo haber hecho nada para evitar que la vulneración de los derechos fundamentales se produjese.

Al respecto, creemos firmemente que la ajenidad no justifica la imposición de tamaña responsabilidad a la empresa principal, y que el principio protector en materia laboral no es un principio irrestricto, de tal forma que la protección a la parte contratante más débil no puede tener como contraefecto el cometer una injusticia mayor que no darle protección, como lo sería el responsabilizar de una vulneración de derechos fundamentales a un agente que no ha tenido participación en los hechos.

Precisamente por lo anterior, es que el motivo por el cual el legislador en el artículo 183-B no hace referencia al pago de las sanciones que acarrean los procedimientos de tutela laboral, es porque no pretende que la empresa principal responda por este tipo de actos ni aun en forma subsidiaria, al tomar en consideración la imposibilidad de acción en la cual se estaría dejando a la empresa principal, al no poder esta impedir la realización de un acto vulneratorio a los derechos fundamentales de un trabajador de la empresa contratista, ni aun ejerciendo a plenitud el derecho de información que le entrega la ley, ya que la empresa principal no se relaciona jerárquicamente con los trabajadores de la empresa contratista ni ejerce sobre ellos facultades propias de su empleador, siendo solo un mero tercero beneficiario de sus servicios.

De esta forma, al exigirle a la empresa principal una reparación por un acto en el que esta ejerció todas las herramientas de control que la ley le entrega, y en el cual no tuvo ninguna participación, se le pretende situar en una hipótesis de responsabilidad objetiva, es decir, que la empresa principal responda independientemente de su conducta, en circunstancias que nuestro ordenamiento jurídico establece este tipo de responsabilidad solo excepcionalmente y mediante texto expreso ${ }^{39}$. Así, no encontrándose tal responsabilidad expresamente establecida en el artículo 183-B, en ningún caso podría interpretarse, de buena fe, que el citado artículo contempla semejante responsabilidad, ni tampoco que la reparación

39 Corral, Hernán. Lecciones de Responsabilidad Civil Extracontractual. Santiago, Chile: Editorial Jurídica de Chile, 2003, p. 222. A mayor abundamiento, la Iltma. Corte de Apelaciones de Santiago ha fallado que la responsabilidad objetiva "no puede establecerse con una interpretación extensiva de las normas legales, pues por ser de carácter excepcional, debe establecerse en forma expresa". Corte de Apelaciones de Santiago, 31 de enero de 1992, RDJ t. LXXXIX, sex. 2a, página 13. 
al daño ocasionado a un trabajador por la vulneración a uno de sus derechos fundamentales forma parte de esta norma.

\section{DOCTRINA Y JURISPRUDENCIA}

Como afirmamos al comienzo de este trabajo, nuestra hipótesis no radica en que la empresa principal no pueda responder en caso de vulneraciones a los derechos fundamentales de los trabajadores de la empresa principal, sino que solamente debe responder quien cometió actos que vulneraron tales derechos, no siendo legal, ni justo, que en el marco de una relación laboral de subcontratación la empresa principal deba de responder por el solo hecho de existir una relación laboral de carácter triangular, ya que en tal caso las sanciones que establece el artículo 489 del Código del Trabajo exceden a lo establecido por el artículo 183-B del mismo cuerpo legal.

Muy a nuestro pesar, la hipótesis que planteamos ha encontrado muy poco asidero en nuestra jurisprudencia nacional, la cual en forma reiterada ha acogido fallos que aceptan la responsabilidad de la empresa principal en el procedimiento de tutela laboral, aun cuando esta no haya tenido ningún grado de participación en los actos vulneratorios de garantías constitucionales.

Así, el $2^{\circ}$ Juzgado de Letras del Trabajo del Trabajo de Santiago ha fallado que ${ }^{40}$ :

"Decimoquinto: Que además resulta lógico que la principal responda de este tipo de indemnizaciones por cuanto se ha aprovechado de los servicios de los trabajadores de la contratista sin ser considerada empleadora, por lo que su responsabilidad (solidaria o subsidiaria) viene a ser la moneda de cambio de esta concesión legal que lo libera del peso que significa administrativamente tener todos los trabajadores a su cargo, estando además en una inmejorable situación de subrogarse de los derechos del trabajador para repetir contra la contratista”.

El fallo anterior fue ratificado por la Iltma. Corte de Apelaciones de Santiago, al señalar en su considerando 7) que el artículo $183-\mathrm{B}^{41}$ :

“7) Que el recurso de autos denuncia, como ya se indicó, la infracción de una única norma legal, cual el artículo 183 B del Código Laboral, que es del siguiente tenor: "La empresa principal será solidariamente responsable de las obligaciones laborales y previsionales de dar que afecten a los contratistas a favor de los trabajadores de estos, incluidas las eventuales indemnizaciones legales que correspondan por término de la relación laboral. Tal responsabilidad estará limitada al tiempo o período durante el cual el o los trabajadores prestaron servicios en régimen de subcontratación para la empresa principal". Se trata, como puede apreciarse, de una norma legal de amplio al-

\footnotetext{
40 "Lara con Agrícola Concha y Toro". 4 de marzo de 2011. T-380-2010. 20 Juzgado de Letras del Trabajo.

41 No Reforma Laboral 455-2011, del 5 de julio de 2011, pronunciada por el Ministro señor Mario Rojas González, por la Ministra señora Pilar Aguayo Pino y por el abogado integrante señor Rodrigo Asenjo Zegers.
} 
cance, y los términos generales en que se encuentra redactada permite perfectamente aplicarla a un caso como el de la especie, por lo que no existe la infracción legal que se denuncia, cuando se la ha interpretado en un determinado sentido".

Otro fallo del $2^{\circ}$ Juzgado de Letras del Trabajo de Santiago ${ }^{42}$, estableció que la empresa principal solo debe responder en aquellos casos en que es el afectado quien tiene derecho a recibir la indemnización, limitación que ciertamente no cuenta con ningún asidero legal:

"Decimocuarto: Que respecto de la responsabilidad de la empresa Moller y Pérez Cotapos se estima que esta solo puede responder de las remuneraciones a que ha sido condenado el Sr. Chiyong, por cuanto la multa a beneficio de SENCE resulta ser una sanción imputable solo al infractor de la libertad sindical y no puede estimarse comprendida dentro del art. 183 B del código del trabajo por cuanto no está establecida a favor del trabajador".

A su vez, el mismo fallo ${ }^{43}$ estableció que la empresa principal puede responder subsidiariamente de dichas vulneraciones si es que ejerce adecuadamente su derecho de información y retención, aun cuando, como ya hemos establecido a lo largo del trabajo, ambos derechos no guardan ninguna relación con la facultad de impedir o prevenir la vulneración de los derechos fundamentales de los trabajadores de la empresa contratista: "Decimoquinto: Que además la responsabilidad de la empresa mandante será de tipo subsidiaria, por cuanto ha acreditado, con el certificado de cumplimiento respectivo y la declaración del testigo Sr. Bernal, que ha hecho uso de los derechos de información y retención en la forma y oportunidad legal".

Como es posible apreciar, acorde con los fallos citados anteriormente, la opinión de nuestra judicatura es que la empresa principal debe de responder en el evento de existir una vulneración a los derechos fundamentales de la empresa contratista, aun cuando no exista verdaderamente un criterio definido por el cual la empresa principal debería de responder en este procedimiento, siendo quizás la razón más clara la señalada por la Corte de Apelaciones de Santiago, al establecer que el artículo 183-B es de "amplio alcance" 44 , lo cual no pareciese ser una razón lo suficientemente convincente como para imponer semejante carga a la empresa principal.

Los fallos señalados con anterioridad van absolutamente en contra de lo que la doctrina nacional ha señalado al respecto, la cual es conteste en señalar que la empresa principal, en su calidad de tal, no tiene ninguna responsabilidad en el procedimiento de tutela de derechos fundamentales, toda vez que quien debe responder de la vulneración de derechos

42 "Lara con Chiyong" 19 de marzo de 2010. T-401-2010. 20 Juzgado de Letras del Trabajo.

43 "Lara con Chiyong" 19 de marzo de 2010. T-401-2010. 20 Juzgado de Letras del Trabajo.

44 Contrario a esta postura se muestra una reciente jurisprudencia de la Corte Suprema, la cual señala en su considerando octavo que las obligaciones laborales y previsionales son aquellas que: "Las que naturalmente surgen para el empleador como consecuencia de la vinculación laboral, para que proceda a su cumplimiento, no es posible comprender entre ellas otro tipo de obligaciones que no revisten ese carácter". "Vásquez con S.A.CA.F. Limitada" 1 de junio de 2011. Rol 8117-10. Excma. Corte Suprema. 
fundamentales de un trabajador es su empleador. Si bien la hipótesis que planteamos en este trabajo es más amplia que lo anteriormente expuesto, nos parece que tal raciocinio apunta en el sentido correcto, al no exigirle reparación a una parte que no se ha visto involucrada en los hechos en disputa.

Así, Juan Carlos Ferrada y Rodolfo Walter Díaz han señalado que "la protección de los derechos fundamentales del trabajador establecida en este Código, a través de este procedimiento especial de tutela, sería en contra de las actuaciones ilícitas y lesivas del empleador" " 5 . José Luis Ugarte ha señalado que "cabría sostener que no corresponde que se ejerza la acción de tutela en contra de la empresa principal atendida su desconexión legal con las facultades propias del empleador, por disposición expresa de las normas que regulan el régimen de subcontratación laboral en Chile" ${ }^{46}$, y que la pretensión procesal de protección de derechos fundamentales busca reparar el daño producido por su vulneración "cuando dicha afectación provenga del ejercicio de las facultades que la ley le reconoce al empleador" 47 .

Por su parte, Eduardo Caamaño ha sido muy claro en señalar que la verdadera complejidad en materia de tutela laboral se da en los trabajadores de servicios transitorios, toda vez que:

"es indudable que la eficacia de los derechos fundamentales se materializa también sin mayores complejidades dogmáticas respecto de la subcontratación de bienes y servicios de las que se ocupan los artículos 183-A a 183-E del CdT, toda vez que, de acuerdo a lo ya precisado, en esta particular forma de tercerización no se ven alterados los supuestos ni los elementos definidores de una relación laboral normal fundada en el contrato individual de trabajo que define el artículo 6 del $\mathrm{CdT}$, siendo por tanto el único empleador la empresa contratista o la subcontratista, en su caso" ${ }^{48}$.

Finalmente, Sergio Gamonal ha seguido la corriente doctrinaria aquí descrita, afirmando que el ámbito de aplicación del procedimiento de tutela laboral: "se aplicará respecto de las cuestiones suscitadas por aplicación de las normas laborales, cuando los derechos humanos que expresamente se mencionan resulten lesionados en el ejercicio de las facultades el empleador" 49 .

Así, las posturas doctrinarias y jurisprudenciales se muestran distantes y no parecen tener ningún punto de encuentro. Por una parte, la jurisprudencia se muestra conteste en

\footnotetext{
45 FERradA, Juan Carlos y DIAZ, Rodolfo. "La protección de los derechos fundamentales de los trabajadores en el nuevo procedimiento de tutela laboral", en: Revista de Derecho, vol. XXIV, n² 2, diciembre 2011, Valdivia, Chile, p. 100.

46 UgarTe, José Luis. Tutela de Derechos Fundamentales del Trabajador. Santiago, Chile: LegalPublishing, 2010, p. 32. Según el mismo autor, lo anteriormente dicho tiene dos excepciones: restricciones a los derechos fundamentales del trabajador que vengan impuestos por la empresa principal en materia de higiene y seguridad, ya que por expresa disposición legal del artículo 183 E del Código del Trabajo, la empresa principal debe responder; la segunda, es en el caso de ejercicio ilegal de facultades propias del empleador por parte de la empresa principal.

47 Ugarte, José Luis. "La Turela de Derechos Fundamentales y el Derecho del Trabajo: De Erizo a Zorro", en: Revista de Derecho vol. XX, $\mathrm{n}^{\circ} 2$, diciembre 2007, Valdivia, Chile, p. 62.

48 CaAmaño, Eduardo, op. cit. (n. 7), p. 175.

49 Gamonal, Sergio. Procedimiento de Tutela de Derechos Laborales. Santiago, Chile: LegalPublishing, 2008, p. 22.
} 
señalar que la empresa principal debe responder en el procedimiento de tutela laboral ${ }^{50}$, mientras que por otro lado, la doctrina señala que en esta materia solo debe responder el empleador, es decir, no la empresa principal.

Creo que hemos sido lo suficientemente enfáticos en señalar que nos parece que la actual postura jurisprudencial es errónea. Sin embargo, la actual posición doctrinaria también nos parece cuestionable, ya que no estimamos que la empresa principal se encuentre absolutamente exenta de responsabilidad. En efecto, creemos que dicha posición doctrinaria se deba a que, con la excepción de José Luis Ugarte, jamás se vislumbró el problema que el presente trabajo plantea, limitándose simplemente a señalar que es el empleador quien debe responder de alguna vulneración a los derechos fundamentales del trabajador, como así pareciese establecer expresamente el inciso tercero del artículo 485 del Código del Trabajo ${ }^{51}$.

Sin embargo, y siguiendo en esta materia a lo señalado por José Luis Ugarte ${ }^{52}$, creemos que la empresa principal sí puede verse en la obligación de responder de una vulneración a los derechos fundamentales de los trabajadores de la empresa contratista, en el caso de que se arrogue facultades propias del empleador, emitiendo órdenes e instrucciones que sobrepasaran el ámbito de las normas de higiene y seguridad, y que lesionaran los derechos fundamentales de trabajadores de la empresa contratista, como por ejemplo, un instructivo que estableciese que todos los trabajadores extranjeros de la empresa contratista deberán ser revisados al término de la jornada para evitar la sustracción de material de la empresa.

De la misma forma que no es sensato sostener que la empresa principal debe responder en estos casos por el solo hecho de existir una relación laboral triangular, tampoco es correcto plantear de antemano que la empresa principal nunca puede responder, toda vez que en la gran mayoría de los casos de subcontratación los trabajadores de la empresa contratista tienen un trato directo con representantes de la empresa principal, por lo que se dan las condiciones que pudiesen propiciar una vulneración a los derechos fundamentales de un trabajador. Así, mediante esta interpretación, se hace posible abrir la acción de tutela, y no limitarla exclusivamente al empleador de los trabajadores, sino que a lo que creemos que es lo que resulta más lógico: que la acción de tutela de derechos fundamentales pueda dirigirse en contra de toda parte de la relación laboral que tuvo participación en los hechos denunciados.

\footnotetext{
$50 \mathrm{Al}$ respecto, conviene tener presente que cuando la vulneración de derechos fundamentales no ocurre bajo el contexto de la subcontratación, muchos fallos de los juzgados de letras del trabajo han señalado igual conclusión que la doctrina aquí citada: en el procedimiento de tutela laboral debe responder el empleador. A modo meramente ejemplar, ver causa "Sánchez con

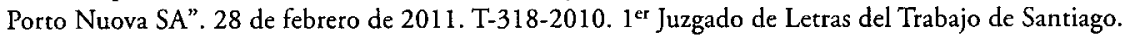

51 Artículo 485 del Código del Trabajo, inciso tercero: "se entenderá que los derechos y garantías a que se refieren los incisos anteriores resultan lesionados cuando el ejercicio de las facultades que la ley le reconoce al empleador limita el pleno ejercicio de aquellas sin justificación suficiente, en forma arbitraria o desproporcionada, o sin respeto a su contenido esencial. En igual sentido se entenderán las represalias ejercidas en contra de trabajadores, en razón o como consecuencia de la labor fiscalizadora de la Dirección del Trabajo o por el ejercicio de acciones judiciales".
}

52 UgarTe, José Luis. Tutela... (n. 47), p. 32. 


\section{LA SENTENCIA QUE DEBIESE DE MARCAR EL CAMINO: EL FALLO SKY LINE ${ }^{53}$}

Pasando demasiado desapercibido en lo que a nuestra opinión concierne, el Juzgado de Letras del Trabajo de Calama, el año 2010, tuvo en su conocimiento un juicio con semejantes presupuestos fácticos que los descritos en los fallos anteriormente citados: un trabajador de una empresa contratista demanda solidariamente a la empresa principal, en virtud del artículo 183-B del Código del Trabajo, producto de que su empleador vulneró sus derechos fundamentales. A este respecto, la solución otorgada por el tribunal es exactamente igual a lo planteado en este trabajo, lo que ciertamente resulta reconfortante para nosotros y un anhelo de que nuestra jurisprudencia adopte tal criterio en forma mayoritaria.

En el caso en cuestión, don Manuel Peña demandó a la Constructora e Inmobiliaria Casa Grande Ltda, y solidariamente a la empresa Sky Line, producto de una vulneración a sus derechos fundamentales referidos a su integridad física y psíquica, a raíz de los insultos y golpes que don Manuel Peña recibió por parte de don Jaime Rubio, representante de Constructora e Inmobiliaria Casa Grande Ltda. En la sentencia definitiva, el considerando vigésimo tercero resulta particularmente revelador respecto a lo improcedente que resulta que la empresa principal deba responder por este tipo de actos:

"Vigésimo Tercero: Que, en cuanto a la pretensión de condenar solidariamente a Sky Line a las pretensiones demandadas en denuncia de vulneración de derechos fundamentales, esta debe ser rechazada, toda vez, que en primer lugar el vulnerar derechos fundamentales es un actuar personal y directo de responsabilidad únicamente de quien realiza los actos vulneratorios y segundo de conformidad a las normas de subcontratación la responsabilidad de la empresa mandante solo dice relación con obligaciones laborales y previsionales, que se generan como consecuencia de la prestación de servicios en los términos del artículo 7 del Código del Trabajo y no como sanción a ilícitos laborales".

En nuestra opinión, esta sentencia resulta particularmente destacable, ya que establece dos criterios que marcan la línea de todo lo expuesto en el presente trabajo: que el vulnerar derechos fundamentales es un actuar personal y que la sanción impuesta por tal vulneración exceden las "obligaciones laborales y previsionales" a las que se refiere el artículo 183-B del Código del Trabajo. Si bien, por ahora, es una postura bastante minoritaria en nuestra jurisprudencia, esperamos que dé el inicio a una nueva corriente jurisprudencial en torno a esta materia, que logre ponderar en forma más equitativa la afectación a un derecho fundamental de un trabajador de la empresa contratista con la participación en los hechos de la empresa principal.

53 "Peña con Constructora Inmobiliaria Casa Grande LTDA y Otra". 26 de abril de 2010. T-13-2009. Juzgado de Letras del Trabajo de Calama. 


\section{8.- CONCLUSIÓN}

En conclusión, deseamos reafirmar la hipótesis sostenida al inicio de este trabajo, respecto a que la empresa principal no debe de responder, ni siquiera subsidiariamente, en caso de una condena por vulneración de derechos fundamentales de un trabajador de la empresa contratista, sino que solamente debiera responder el agente que realizó la acción vulneratoria.

Ante ello, deberemos estar atentos a la evolución jurisprudencial de nuestros tribunales en esta materia, para así saber si es que se continuará fallando en torno a lo más conveniente para el trabajador afectado, o si es que se tomará en consideración el hecho de que ninguna persona o entidad debiese de hacerse responsable por hechos sobre los cuales no tuvo participación, si es que la ley no le impone tal obligación. Ciertamente, es un tema sobre en donde existe mucho espacio para interpretar, y sobre el cual esperamos un cambio de criterio por parte de los juzgados de letras del trabajo de nuestro país. 